\title{
The Application of "3S" (GIS, RS and GPS) Technology to the Study of China FangZhen Period
}

\author{
Wei Cheng ${ }^{\mathrm{a}}$ \\ ${ }^{a}$ Department of tourism,resouces and environment, Zaozhuang University, Zaozhuang, Shandong Province, \\ China
}

\begin{abstract}
This paper sets out to explore the potential of "3S" (GIS, RS and GPS) technology in the area of historical geography studies in particular. During the later years of Tang dynasty the most of lands between Yellow River and Yangtze River suffered a chaotic juxtaposition of separatist regimes, i.e., FangZhen. By using relevant vector data, GPS data and remote sensing satellite imaginary on the appropriate platform of GIS, we improved the quality and accuracy of scientific studies of FangZhen Period much more than before. Tang FangZhen Information System, a focused custom GIS system, has also been developed here to explore the formation and development of FangZhen. GIS processes such as area, point and line representation and tracing, image/feature/script hotlinking and thematic representation are perfect to trace and display historical data across space.
\end{abstract}

Index Terms: “3S” Technology; ArcEngine 9.3; FangZhen Period

(C) 2011 Published by MECS Publisher. Selection and/or peer review under responsibility of the International Conference on E-Business System and Education Technology

\section{Introduction}

Writing about the state of historical geography in 1997, Ogborn [1] made no mention of the use of Geographical Information Systems (GIS) in the discipline. This was not a significant omission because at the time the application of GIS to the study of historical geography, as the topic has since become known, was in its infancy. Since then it has grown rapidly and is becoming increasingly acknowledged as an important development in historical geography. It received significant amounts of attention in Holdsworth's two more recent reviews of the state of historical geography [2] [3], while Baker [4] describes it as 'an exciting and challenging development'. It seems opportune, therefore, to describe the current state of historical GIS and to examine the challenges it faces [5].

Many historians and historical geographers regard GIS as primarily being concerned with mapping. Although mapping is one of the key abilities of GIS, it is perhaps better regarded as a database technology. A

Corresponding author:

E-mail address: 
GIS is a specialized form of database because each item of data, be it a row of statistics, a string of text, an image, or a movie, is linked to a coordinate-based representation of the location that the data refer to. Thus GIS combines spatial data in the form of points, lines, polygons, or grid cells, with the attribute data held in conventional database form. This provides a structure that is able to answer queries not only about what features are in the database, but also about where they are located. This is what makes GIS unique [6] [7].Gregory et al. [8] identified three advantages of using GIS in historical research. First, as spatial data tell us where the data are located this can be used to structure a database and to integrate seemingly incompatible data simply through where they are placed on the Earth's surface. Second, it allows data to be visualized using maps and more advanced techniques such as animations and virtual landscapes. Third, GIS enables forms of spatial analysis where the coordinate locations of the features under study are an explicit part of the analysis.

\section{Study Area And Methodology}

The Tang Dynasty was one of the great ages of development and consolidation in China. It looked back to other periods of transformation and cultural flowering, the ancient Dynasties of Shang and Chou, and the historical achievements of Ch'in and Han. Tang dynasty was at its greatest extent during LongShuo Period (661-664 AD) which Emperor Gaozong controlled the territory from Amur in the east to Caspian Sea in the west and from somewhere around Angara river or Stony Tunguska river in Siberia in the north to central Vietnam in the south.

However, the splendid appearance covered up the depravity. By the eighth century, during the later part of Emperor Xuanzong's reign, the Tang Empire was in decline. After the rebellion of An-Shi, The separatist reigns of FangZhen severely weakened the ruling strength of the Tang Empire during the closing years.

How about the formation and development of FangZhen? The spatial aspect in this problem lends itself well to applications of geographic information systems (GIS). This paper presents an Application of GIS to the study of FangZhen.

The application of GIS can help to enhance effectively efficiency and precision, therefore the whole quality of research, in historical geography study. With development tools of ArcGIS Engine 9.3 and VS.NET, we set up an information system about the FangZhen Period of Tang dynasty to explore its formation and development.

\section{Implemention and Result}

According to the 1:4M-scale Topographic Database of the National Fundamental Geographic Information System of China, we can locate the modern Xian city rapidly, then redefine the projection coordinate system in ArcToolBox (For the GeoCover Landsat mosaics are delivered in a Universal Transverse Mercator (UTM) / World Geodetic System 1984 (WGS84). Xian city is in the WGS 1984 UTM Zone 49N and The 1:4M-scale Topographic Database projection coordinate system is "Xian 1980"). Overlapped the 1:4M-scale topographic vector data with GeoCover Landsat mosaics (raster image), finally we get the Xian city on the satellite image.

Because ChangAn city was strictly bilaterally symmetrical, and the rectangular walled city was laid out like a giant chessboard, after we get the position of the XinQin Palace on the satellite imaginary and of Big Wild Goose Pagoda in the Geographic Names File, combined with the locations of several remains of Tang capital city ChangAn ( in now Xian).

We've acquired by GPS (GARMIN GPS76 accuracy: Position: < 15 meters, 95\% typical), like the southern MingDeMen $\left(108^{\circ} 56^{\prime} 7^{\prime \prime} \mathrm{E}, 34^{\circ} 12^{\prime} 117^{\prime \prime} \mathrm{N}\right)$, the western KaiYuanMen $\left(108^{\circ} 53^{\prime} 6^{\prime \prime} \mathrm{E}, 34^{\circ} 16^{\prime} 5^{\prime \prime} \mathrm{N}\right)$, the northern XuanWuMen $\left(108^{\circ} 56^{\prime} 14^{\prime \prime} \mathrm{E}, 34^{\circ} 17^{\prime} 11^{\prime \prime} \mathrm{N}\right)$, we can quickly draw out the accurate size and layout of the then ChangAn city. "According to field measure, Tang ChangAn city is a EW9721m*NS 8651m," this measurement accord with the result we get in Arcmap: EW9740*NS 8781m (take into consideration errors from GPS location, redefining of coordinate system and the resolution ambiguity of raster image). 
As illustrated in Fig.1, the straight line indicates the central urban area of modern Xian city, while the dotted line indicates the capital city ChangAn of Tang Empire. The latter surpasses the first by far in scale and provokes remote imagination of the prosperity and magnificence of ChangAn city as one of the few then metropolises populated by one million.

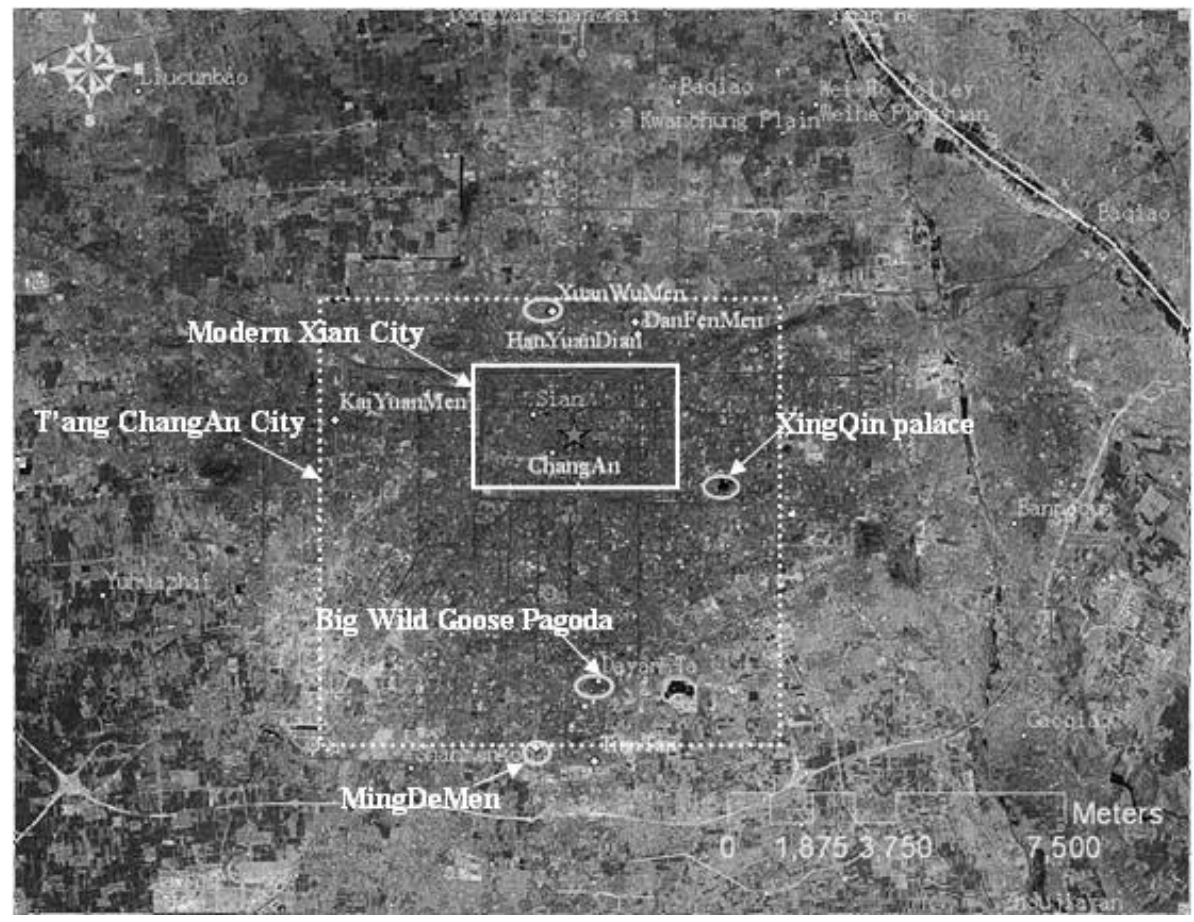

Fig. 1. Capital of Tang Empire—ChangAn City

In $627 \mathrm{AD}$, Emperor Taizong zoned the country into ten circuits i.e. Dao (see Table 1) demarcated by geographical features, say, mountains or rivers.

Table 1. Ten Circuits (Dao) of the Tang Empire 627 Ad

\begin{tabular}{cl}
\hline circuit & \\
\hline Guannei & Ningxia, Shaanxi province \\
Henan & Eastern Henan, Shandong province \\
\hline Hedong & Western Henan, Shanxi province \\
\hline Hebei & Beijing, Tianjin, Hebei province \\
\hline Longyou & Eastern xinjiang, Gansu, North-western Qinghai province \\
\hline Shannan & Hubei, Northen Sichuan province, Chongqing \\
\hline Huainan & Northern Jiangsu, Northern Anhui province \\
\hline Jiangnan & Southern Jiangsu, Southern Anhui, Shanghai, Zhejiang, Fujian Jiangxi, Hunan, Guizhou province \\
\hline Jiannan & Southern Sichuan province \\
\hline Lingnan & Guangxi, Guangdong, Hainan province \\
\hline
\end{tabular}


In $733 \mathrm{AD}$, another five circuits were added(see Fig.2), among which, ShanNan circuit is subdivided into eastern and western parts, JiangNan circuit into eastern, western and QianZhong parts, and a new JingJi circuit separated from GuanNei circuit, a new DuJi circuit from HeNan circuit. Apart from the fifteen circuits, vast areas in the North and Northwest are occupied by Turks. The empire of Tubo held the southwest under control. In the southeast hilltribes sometimes said to be ancestors of the modern Thai were untied in the kingdom of Nanzhao that occupied modern Yunnan and the north of Laos, Thailand and Burma. The modern northeast three provinces of China and far-east areas in Russia were inhabited by nationalities of Khitan (QiDan) and Parhae (BoHai).
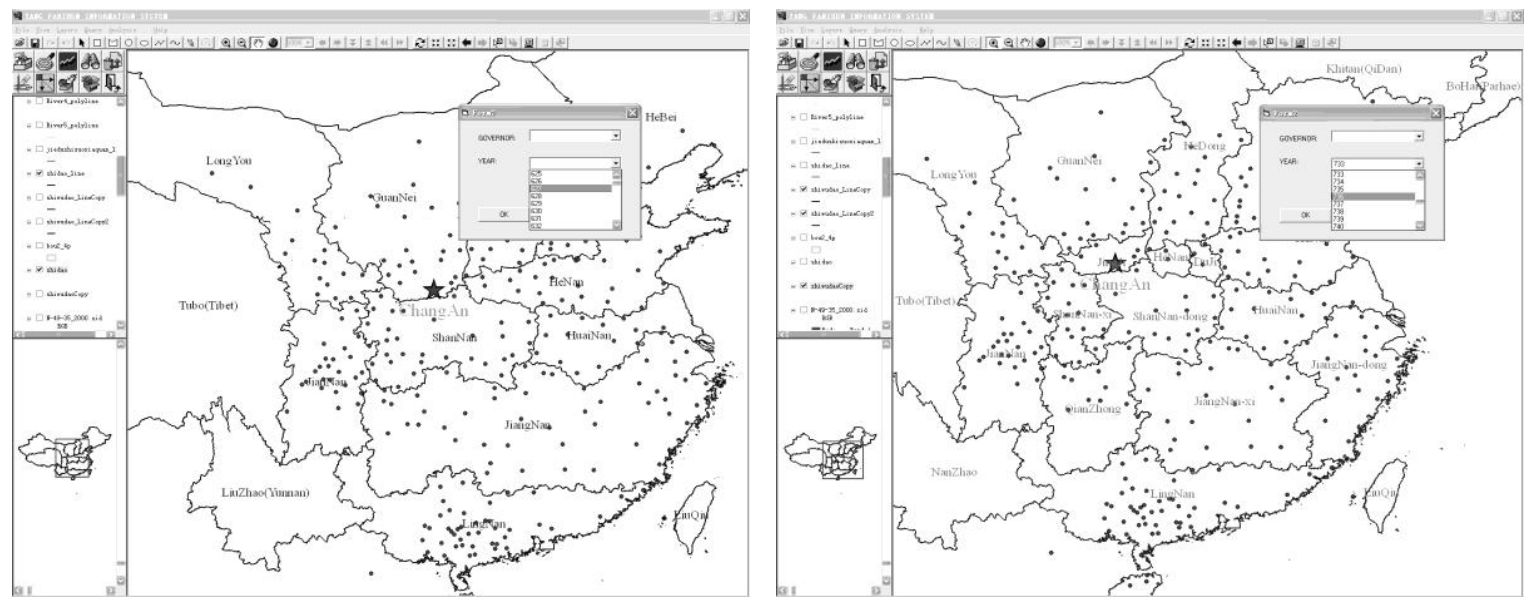

Fig. 2. The panoramic picture of Tang Empire in 627AD and $733 \mathrm{AD}$

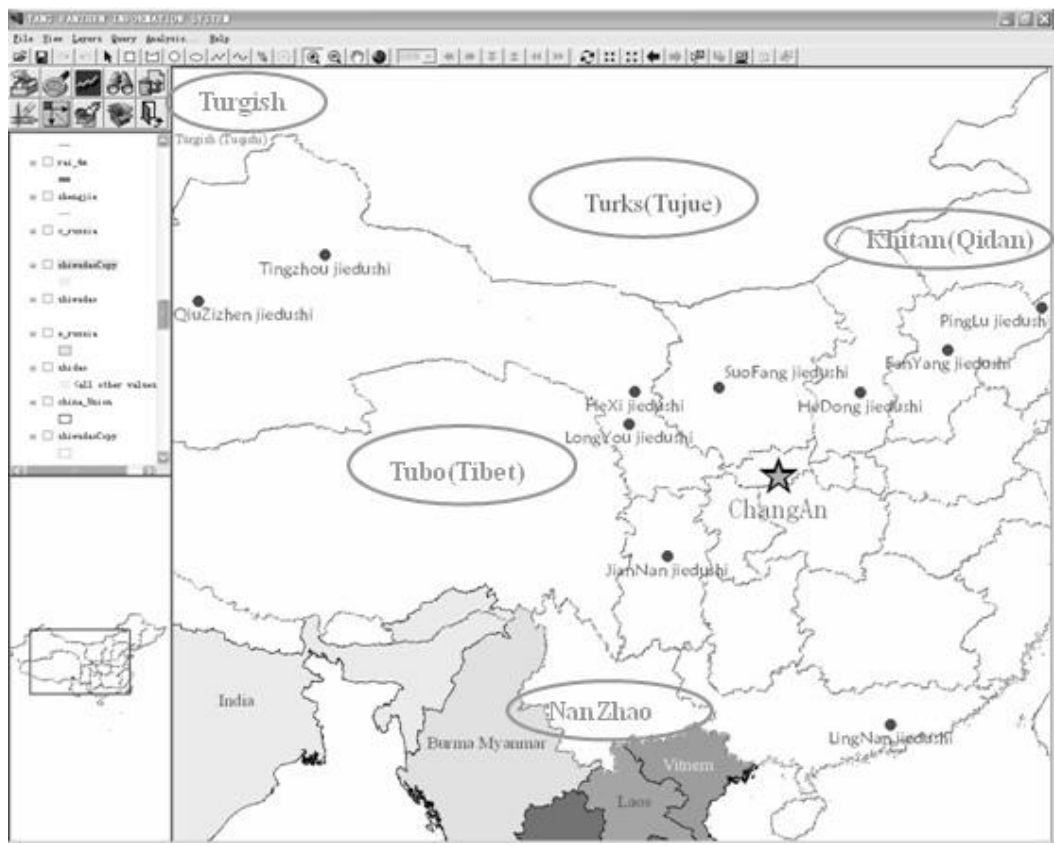

Fig. 3. Tang Empire just on the eve of the Rebellion of An-Shi 
During 710-755AD, many fortresses, were established to improve the frontier protections in some key areas along the Tang Empire border (see Fig.3). Originally "Jie Du Shi" was the title given to those who were placed in charge of fortresses and they were given the task of protecting the empire's frontiers. The "Jie Du Shi" were given enormous power. Periodically, a censor appointed by the central government would inspect local administration. In this way, governors who performed well could be assured of promotion. With the passing of time and the decline of court, the influence of the fortress increased. Until the Rebellion of An-Shi, over 90 percent of the military army was under the control of "Jie Du Shi". The central government gradually lost its control over regional administration and in particular, control of the military commands along the northwestern frontiers.

The governing sites of Ten "Jie Du Shi" during TianBao Period (742-755 AD) are marked with black spots. As inferred from Fig3, those "Jie Du Shi" were instituted to defend against northern nomadic peoples such as Khitan (QiDan) on the North border, Turks and Turgish on the North and Northwest, Tubo on the west, etc, and southern barbarians, like the kingdom of NanZhao on the Southwest.

During and after the "An-Shi" rebellion (In 755AD, An Lushan, a trusted "Jie Du Shi", led a rebellion in Fanyang, modern Beijing, with a view to ending the corrupt rule by Yang Guozhong. The civil war lasted for eight years, and was very destructive), the Tang central government increased the total number of "Jie Du Shi" in such provinces as HuBei, AnHui, Jiangsu, HeNan and ShanDong to defeat the rebel army and beat down other small-scale rebellions. The Tang emperors were obliged to pay a high price for their loyalty: The "Jie Du Shi" were allowed to establish their own troops, to collect taxes. They were also able to install their own sons as hereditary successors to their military positions. Many areas controlled by "Jie Du Shi" only nominally adhered to the Tang regime, as they established themselves as separatist regimes, so called FangZhen. These FangZhen, relying on their military power and financial ability, attacked each other and even antagonized the central government. Thus, the inter-FangZhen conflict coupled with the fighting against the forces of the central government endured until the final destruction of the Tang regime.

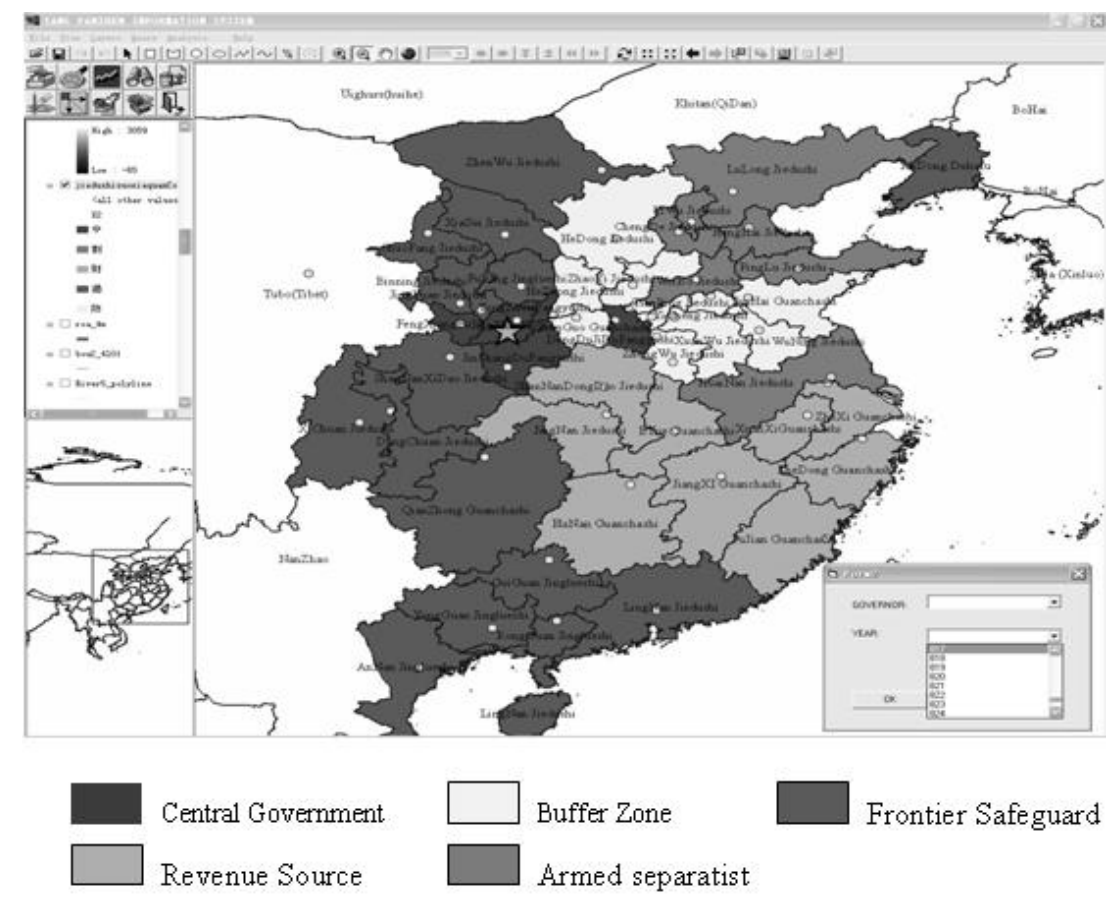

Fig. 4. The reigns of FangZhen during the ZhenYuan Period (785-805AD) 
As illustrated above, the Northwest part of Tang Empire had been annexed by Tubo, Turks was replaced by Uighurs in the north, Khitan (QiDan) and Parhae (BoHai) occupies the Northeast. The most of lands between Yellow River and Yangtze River suffered a chaotic juxtaposition of separatist regimes, i.e. FangZhen. Under the direct control of central government were limited areas like the south of ShaanXi province, vicinities of Luoyang in HeNan province. But not all of FangZhens acted separatists, as the majority of them in modern ShanXi, SiChuan and those situated to the south of Yangtzs River and HuaiHe River obeyed the command from central government, where the latter held control of the local taxes, receive regular tributes and decided on official personnel changes[9]. All in all, FangZhens can be categorized into four groups (see Fig.4):

Armed separatist regimes: they don't abide by orders from above, nor hand in taxes or tributes, confronting against the central government on a long term, even launch large-scale wars.

Buffer zone regimes: they are loyal to the central government. As they have common border with armed separatist regimes, further disadvantaged by barren land and small population, they mainly function as buffer zone between central government and separatist regimes, and at the same time protect the smoothness of river transportation from warfare.

Frontier safeguard regimes: as they are faced with nomadic peoples and barbarians, plus adverse economic and natural conditions, they need martial and logistical support of central government in arm force, equipments and supplies, whose primary role is to relieve the threat nomadic peoples and barbarians pose to inner plains.

Revenue source regimes: Among this group, except that a few short-termed FangZhens relying on their strong strength defy and even rebel against the central government, for the most part they follow the directions from central government. They possess superb geographical positions, fertile land and large population, convenient transportation and particularly waterways, so they become the pillar source of national revenue.

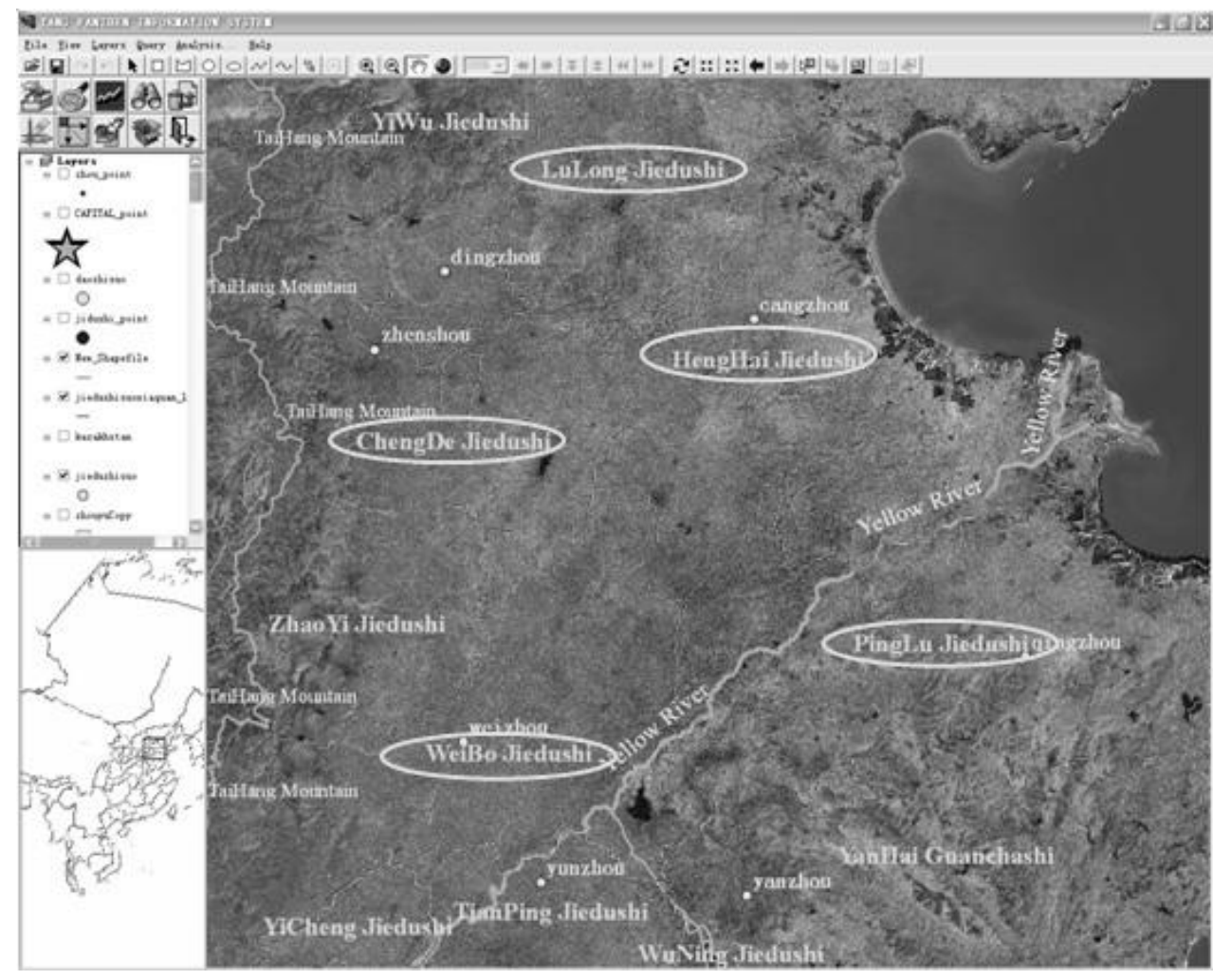

Fig. 5. Separatist Regimes boast geographical advantages (785-805AD) 
Judging from Fig.5, it's obvious that separatist regimes, as marked by ellipse, boast geographical advantages, bounded by torrential Yellow River in the south, vast expanse of ocean in the east, TaiHang Mountain standing like a natural screen in the west, only leaving the north subject to the attacks from nomadic peoples. Separatist regimes occupy the North-China Plain, of which the natural and material conditions top in the whole empire, with fertile land, affluent produces and intensive population. The population of regions governed by the five "JieDuShi", i.e., FangZhen as marked in the picture makes up 25\%-30\% of the total [10]. Therefore, crusades Tang Emperors launch repeatedly end up in vain, and they have to recognize the virtually independent identity of these separatist regimes.

\section{Discussion and Conclusions}

The application of 3S (GIS, RS, GPS) can help to enhance effectively efficiency and precision, therefore the whole quality of research, in historical geography study. This paper has discussed how to apply information technologies to explore questions in historical geography studies. Surely, owing to the relative precision of data, mainly spatial data, (influenced by errors and limits related to transformation of coordinate system, GPS location and the resolution ambiguity of raster image), the accuracy of our research result fall far behind an ideal level. Besides, the multitude of data (with both spatial and temporal dimensions, data multiplies exponentially) bring about many problems in the operations of storing, managing, indexing, enquiring data: the intense consumption of disk space, severe deficiency of system resources, etc, can cause much difficulties in enquiring geographical locations and recovering historical sections. We still need to find more efficient and mature spatio-temporal data structure model and algorithm. But the research tools and methods set forth in this paper blazes a new way in the study of historical geography and forecast a beautiful prospect ahead.

\section{References}

[1] Ogborn M., The relations between geography and history: work in historical geography in 1997. Progress in Human Geography 23, pp.97-108, 1999.

[2] Holdsworth, D.W. Historical geography: the ancients and the moderns generational vitality. Progress in Human Geography 26, pp. 671-78, 2002.

[3] Holdsworth, D.W. Historical geography: new ways of imaging and seeing the past. Progress in Human Geography 27, pp. 486-93, 2003.

[4] Baker, A.R.H. Geography and history: bridging the divide. Cambridge: Cambridge University Press, pp.44, 2003.

[5] Burrough, P.A. and McDonnell, R.A. Principles of Geographical Information Systems. Oxford: Oxford University Press. 1998.

[6] Longley, P.A., Goodchild, M.F., Maguire, D.J. and Rhind, D.W., editors Geographical Information Systems: principles, techniques, management and applications, second edition, Chichester: Wiley.B, 1999.

[7] Worboys, M. and Duckham, M., GIS: a computing perspective. Boca Raton, FL: CRC Press, 2004.

[8] I.N. Gregory and Richard G. Healey, Historical GIS: structuring, mapping and analysing geographies of the past Progress in Human Geography, 31: 638,2007

[9] Guogangzhang, A Study of FangZhen during Tang Dynasty. Hunan Education Press of China (in Chinese), 1987, pp.77-103.

[10] Twitchett Denis. The Cambridge History of China, vol. 3 Sui and Tang China Cambridge, UK: Cambridge University Press, 1979, pp.285-333. 